\title{
PROFIL SKALA KLINIS DAN SUBKLINIS MMPI-2 ADAPTASI INDONESIA PADA MAHASISWA SEMESTER 5 TAHUN AKADEMIK 2012/2013 FAKULTAS KEDOTERAN UNIVERSITAS SAM RATULANGI MANADO
}

\author{
${ }^{1}$ Reni Ch. Ibrahim \\ ${ }^{2}$ Herdy Munayang \\ ${ }^{2}$ Barnabas H. R. Kairupan
}

${ }^{1}$ Kandidat Skripsi Fakultas Kedokteran Universitas Sam Ratulangi Manado
${ }^{2}$ Bagian Psikiatri Fakultas Kedokteran Universitas Sam Ratulangi Manado
Email: reni_christiani@yahoo.com

Abstract: Students often deal with many internal or external demands. These conditions can lead to some academic and non-academic problems which influence their mental health. Depression and anxiety are the most common disorders experienced by students. This was a descriptive study with a cross sectional survey design. This study aimed to obtain the mental status of students of the academic year 2012/2013 Faculty of Medicine University of Sam Ratulangi Manado based on clinical and subclinical scales MMPI-2 Indonesian adapatation. Data were analyzed by using a univariate analysis of the SPPS 20 version. The results showed that of a hundred respondents the majority of them, in terms of socio-demographic data, were females (53\%), age $\leq 20$ (90\%), origins of ethnicity and residences outside North Sulawesi (56\% and 66\%), two siblings and the second born (38\%), while the parents occupations as civil servants (46\% fathers and $49 \%$ mothers). The distribution of MMPI-2 clinical scales showed high profiles with the percentages as follow: Si (28\%), D (27\%), Pt (18\%), Hs and Sc (12\%), Hy (10\%), Pd (7\%), and Mf and Ma (2\%). The greatest proportions of each subclinical scale based on the highest clinical scale scores were: $\mathrm{D}_{1}(88.9 \%), \mathrm{Si}_{1}(82.1 \%), \mathrm{D}_{4}(81.5 \%)$, and $\mathrm{D}_{5}(63 \%)$. Conclusion: Depression and social introversion scales were found as the highest and most predominant scales. Each student who showed a high scale profile should be paid more attention to from the Faculty council in order to prevent them from developing mental disorders.

Keywords: profile, clinical scales, subclinical scales, MMPI-2, students.

\begin{abstract}
Abstrak: Mahasiswa hampir selalu diperhadapkan dengan banyak tuntutan internal dan atau eksternal yang dapat menimbulkan masalah-masalah akademis maupun non-akademis. Setiap masalah tersebut dapat memengaruhi kesehatan mentalnya. Depresi dan kecemasan merupakan gangguan mental yang paling umum dialami oleh mahasiswa. Penelitian ini bertujuan untuk mendapatkan status mental mahasiswa semester 5 Fakultas Kedokteran Universitas Sam Ratulangi Manado TA 2012/2013 berdasarkan skala klinis dan sub-klinis MMPI-2 adaptasi Indonesia. Penelitian ini merupakan penelitian deskriptif dengan menggunakan survei dan cross sectional design. Analisis data berupa analisis univariat dengan menggunakan SPSS 20. Hasil penelitian memperlihatkan bahwa dari 100 responden distribusi mahasiswa berdasarkan sosio-demografik terbanyak pada perempuan (53\%), usia $\leq 20$ (90\%), yang berasal dari daerah dan suku di luar Sulawesi Utara (56\% dan 66\%), 2 bersaudara dan anak ke-2 dalam keluarga (38\%), serta pekerjaan ayah dan ibu sebagai PNS (46\% dan 49\%). Distribusi skala klinis MMPI-2 pada mahasiswa dari semua skala menunjukkan profil yang tinggi dengan persentase berturut-turut dari tinggi ke rendah yaitu: Si (28\%), D (27\%), Pt (18\%), Hs dan Sc (12\%), Hy (10\%), Pd (7\%), serta Mf dan Ma (2\%).
\end{abstract}


Hasil yang menonjol pada skala subklinis berdasarkan skor tinggi skala klinis berturut-turut $\mathrm{D}_{1}(88,9 \%), \mathrm{Si}_{1}(82,1 \%), \mathrm{D}_{4}(81,5 \%)$, dan $\mathrm{D}_{5}(63 \%)$. Simpulan: Berdasarkan skala klinis dan sub-klinis MMPI-2 adaptasi Indonesia, pada mahasiswa semester 5 Fakultas Kedokteran Universitas Sam Ratulangi Manado TA 2012/2013 skala yang tinggi dan skala yang menonjol ialah depression dan social introversion. Setiap mahasiswa dengan profil skala yang tinggi seharusnya mendapat perhatian dari pimpinan fakultas untuk mencegah timbulnya gangguan mental.

Kata kunci: profil, skala klinis, subklinis, MMPI-2, mahasiswa.

Manusia ialah subjek sekaligus objek, serta makhluk individual sekaligus sosial. Masa perkembangan manusia biasanya digambarkan dalam periode-periode tertentu. ${ }^{1,2} \mathrm{Ma}-$ hasiswa digolongkan sebagai remaja akhir dan dewasa awal, yaitu usia 18-21 tahun dan 22-24 tahun. Masa peralihan yang dialami oleh mahasiswa mendorong mahasiswa untuk menghadapi berbagai tuntutan dan tugas perkembangan baru, yang muncul akibat adanya perubahan pada beberapa aspek fungsional individu, yaitu fisik, psikologis, dan sosial. ${ }^{3}$

Erikson membagi perkembangan dalam delapan stadium. Mahasiswa termasuk dalam stadium intimacy versus selfabsorbtion or isolation. Bila resolusi stadium tersebut tidak berhasil maka hal tersebut dapat mencerminkan kegagalan dalam bentuk maladaptive (penyesuaian diri), delinquent (kenakalan), dan deviant (perilaku menyimpang), ${ }^{4}$ yang berlanjut sebagai masalah kesehatan mental.

Mahasiswa hampir selalu diperhadapkan dengan banyak tuntutan internal dan atau eksternal yang dapat menimbulkan masalah-masalah akademis maupun nonakademis. Masalah-masalah akademis terutama disebabkan oleh ketidakmampuan untuk menyesuaikan diri dengan tuntutan dan permasalahan non-akademis, terutama berasal dari tekanan sosial yang dialami mahasiswa sehari-hari. ${ }^{5}$

Menurut data WHO, prevalensi gangguan mental pada populasi penduduk dunia pada tahun 2000 sebesar 12\%, dan pada tahun 2001 meningkat menjadi 13\%. Di Indonesia, hasil laporan Riset Kesehatan Dasar (Riskesdas) 2007memperlihatkan prevalensi gangguan mental emosional pada penduduk Indonesia yang berusia $>15$ tahun sebesar 11,6\%. Studi di Tufts University School of Medicine, Burlington menunjukkan bahwa $27 \%$ dari anak-anak usia kuliah mengalami gangguan kesehatan mental. $^{6-8}$ Jenis gangguan mental paling umum dikalangan remaja dan dewasa muda seperti mahasiswa ialah depresi dan gangguan kecemasan, bahkan sampai stres.

Minnesota Multiphasic Personality Inventory-5 (MMPI-2) ialah tes kepribadian yang paling banyak digunakan secara luas dalam penelitian dan penilaian instrumen dalam psikologi. ${ }^{9,10}$ Skala klinis merupakan skala dengan penilaian objektif, yaitu bagaimana orang lain menilai individu tersebut. Struktur MMPI-2 yang terdiri dari 567 pertanyaan yang dijawab benar atau salah membutuhkan sekitar 6090 menit untuk diselesaikan. Tes MMPI-2 dirancang untuk usia 18 tahun keatas. ${ }^{11}$

\section{METODE PENELITIAN}

Penelitian ini bersifat deskriptif dengan menggunakan survei dan cross sectional design. Penelitian dilaksanakan pada periode Desember 2012-Januari 2013 yang bertempat di Fakultas Kedokteran Universitas Sam Ratulangi Manado. Populasi penelitian yaitu seluruh mahasiswa semester 5 TA 2012/2013 Fakultas Kedokteran yang masih aktif kuliah dengan jumlah total 281 mahasiswa. Sampel sebesar 74 responden diperoleh dengan menggunakan metode simple random sampling (acak sederhana). Pada penelitian ini telah ditetapkan menggunakan sampel penelitian sebanyak 100 orang untuk mengantisipasi adanya sampel penelitian yang tidak memenuhi syarat skala validitas MMPI-2. 
Variabel penelitian ini ialah skala klinis dan subklinis MMPI-2, serta sosiodemografik. Instrumen penelitian yang digunakan ialah informed consent, kuesioner sosio-demografik, dan kuesioner MMPI-2.

Analisis data berupa analisis univariat yaitu mendeskripsikan setiap variabel penelitian dalam frekuensi dan persentase yang disajikan dalam bentuk tabel distribusi. Untuk data berdasarkan skala klinis MMPI2 diserahkan pada psikolog atau psikiater yang telah menerima pelatihan ektensif dalam mengintrepretasi MMPI-2. Untuk analisis data sosio-demografik dan data hasil analisis program MMPI-2 digunakan program SPSS 20.

\section{HASIL PENELITIAN}

Sejumlah 100 responden penelitian telah berespon baik dalam menyelesaikan kuesioner yang diberikan.

Distribusi sosio-demografik pada Tabel 1 memperlihatkan responden perempuan $(53 \%)$ lebih banyak dari laki-laki (47\%). Usia responden berkisar 18-23 tahun, dengan persentase tertinggi pada usia $\leq 20$ tahun (90\%). Responden yangberasal dari daerah dan suku di luar Sulawesi Utara (56\% dan 66\%) berjumlah lebih banyak dibandingkan dari Sulawesi Utara (44\% dan 34\%). Persentase terbanyak ditemukan pada jumlah bersaudara 2 orang dan anak ke-2 dalam keluarga (38\%). Distribusi mahasiswa berdasarkan pekerjaan ayah dan ibu memperlihatkan persentase terbanyak sebagai PNS (46\% dan 49\%) (Tabel 1).

Tabel 2 menunjukkan sebagian besar jalur masuk kuliah yang dipilih responden ialah melalui jalur khusus (53\%). Persentase IPK tertinggi pada responden ialah yang memiliki IPK sedang (2,763,50 ) yaitu sebanyak $73 \%$, dan sebagian besar responden tidak menerima beasiswa saat berkuliah (84\%).

Tabel 3 memperlihatkan persentase tertinggi pada responden yang bertempat tinggal di kos (59\%) dan yang terendah ialah yang bertempat tinggal di rumah saudara $(5 \%)$.
Tabel 1. Distribusi mahasiswa berdasarkan sosio-demografik.

\begin{tabular}{|c|c|}
\hline Variabel & $(\%)$ \\
\hline \multicolumn{2}{|l|}{ Jenis kelamin } \\
\hline Laki-laki & 47,0 \\
\hline Perempuan & 53,0 \\
\hline \multicolumn{2}{|l|}{ Usia (tahun) } \\
\hline$\leq 20$ & 90,0 \\
\hline$>20$ & 10,0 \\
\hline \multicolumn{2}{|l|}{ Asal daerah } \\
\hline Sulawesi Utara & 44,0 \\
\hline Luar Sulawesi Utara & 56,0 \\
\hline \multicolumn{2}{|l|}{ Suku } \\
\hline Sulawesi Utara & 34,0 \\
\hline Luar Sulawesi Utara & 66,0 \\
\hline \multicolumn{2}{|l|}{ Jumlah bersaudara } \\
\hline 1 & 7,0 \\
\hline 2 & 38,0 \\
\hline 3 & 32,0 \\
\hline 4 & 15,0 \\
\hline 5 & 7,0 \\
\hline 6 & 1,0 \\
\hline \multicolumn{2}{|l|}{ Anak ke- } \\
\hline Anak tunggal & 7,0 \\
\hline 1 & 32,0 \\
\hline 2 & 38,0 \\
\hline 3 & 13,0 \\
\hline 4 & 7,0 \\
\hline 5 & 2,0 \\
\hline 6 & 1,0 \\
\hline \multicolumn{2}{|l|}{ Pekerjaan ayah } \\
\hline Tidak bekerja & 2,0 \\
\hline Dokter & 10,0 \\
\hline PNS & 46,0 \\
\hline Wiraswasta & 31,0 \\
\hline Pensiunan PNS & 8,0 \\
\hline Petani & 1,0 \\
\hline POLRI & 1,0 \\
\hline Pelaut & 1,0 \\
\hline \multicolumn{2}{|l|}{ Pekerjaan ibu } \\
\hline Ibu Rumah Tangga (IRT) & 28,0 \\
\hline Dokter & 4,0 \\
\hline PNS & 49,0 \\
\hline Wiraswasta & 14,0 \\
\hline Perawat & 2,0 \\
\hline Pendeta & 1,0 \\
\hline Pensiunan PNS & 2,0 \\
\hline
\end{tabular}

Tabel 3 juga menunjukkan sebagian besar responden tidak mengalami masalah saat berkuliah yaitu tidak mengalami masalah keluarga (88\%), tidak kesulitan dalam bergaul $(96 \%)$, tidak mengalami masalah 
Tabel 2. Distribusi mahasiswa berdasarkan karakteristik akademis.

\begin{tabular}{lc}
\hline \multicolumn{1}{c}{ Variabel } & $(\boldsymbol{\%})$ \\
\hline Jalur masuk kuliah & \\
SNMPTN & 12,0 \\
T2 & 35,0 \\
Jalur khusus & 53,0 \\
IPK & \\
Rendah & 2,0 \\
Cukup & 17,0 \\
Sedang & 73,0 \\
Tinggi & 8,0 \\
Beasiswa saat berkuliah & \\
Ya & 16,0 \\
Tidak & 84,0 \\
\hline
\end{tabular}

dengan dosen (96\%), tidak tertekan oleh senior $(94 \%)$, dan tidak mengonsumsi obatobatan $(94 \%)$. Sebagian besar responden penelitian memiliki kendaraan pribadi ke kampus $(46 \%)$.

Tabel 3. Distribusi Mahasiswa Berdasarkan Karakteristik Non-Akademis.

\begin{tabular}{lc}
\hline \multicolumn{1}{c}{ Variabel } & $(\%)$ \\
\hline Tempat tinggal sekarang & \\
Kos & 59,0 \\
Rumah sendiri & 36,0 \\
Rumah saudara & 5,0 \\
Permasalahan saat berkuliah & \\
Masalah keluarga & \\
$\quad$ Ya & 12,0 \\
Tidak & 88,0 \\
Kesulitan bergaul & \\
$\quad$ Ya & 4,0 \\
Tidak & 96,0 \\
Masalah dengan dosen & \\
Ya & 4,0 \\
Tidak & 96,0 \\
Tertekan oleh senior & \\
Ya & 6,0 \\
Tidak & 94,0 \\
Konsumsi obat-obatan & \\
Ya & 6,0 \\
Tidak & 94,0 \\
Kendaraan ke kampus & \\
Kendaraan pribadi & 46,0 \\
Kendaraan umum & 39,0 \\
Jalan kaki & 15,0 \\
\hline
\end{tabular}

Analisis skala validitas menunjukkan bahwa semua sampel memberikan hasil yang konsisten, akurat, dan dapat dipercaya (valid). Tabel 4 memperlihatkan skala klinis dengan hasil yang tinggi bervariasi berturut-turut dari tinggi ke rendah: $\mathrm{Si}$ (28\%), D (27\%), Pt(18\%), Hs dan Sc (12\%), Hy (10\%), Pd (7\%), serta Mf dan Ma (2\%). Persentase skala klinis dengan hasil yang rendah berturut-turut ialah: Hs (53\%), D (18\%), Hy (44\%), Pd (53\%), Mf (47\%), Pa (40\%), Pt (41\%), Sc (51\%), Ma (65\%), dan Si (13\%).

Tabel 4. Distribusi mahasiswa berdasarkan status mental menurut skala klinis.

\begin{tabular}{|c|c|c|}
\hline Skala klinis & & $(\%)$ \\
\hline \multicolumn{3}{|c|}{ Skala 1 Hs (Hypochondriasis) } \\
\hline \multirow{2}{*}{ T Score } & Tinggi & 12,0 \\
\hline & Rendah & 53,0 \\
\hline \multicolumn{3}{|c|}{ Skala 2 D (Depression) } \\
\hline \multirow{2}{*}{ T Score } & Tinggi & 27,0 \\
\hline & Rendah & 18,0 \\
\hline \multicolumn{3}{|c|}{ Skala 3 Hy (Hysteria) } \\
\hline \multirow{2}{*}{ T Score } & Tinggi & 10,0 \\
\hline & Rendah & 44,0 \\
\hline \multicolumn{3}{|c|}{ Skala 4 Pd (Psycophatic Deviate) } \\
\hline \multirow{2}{*}{ T Score } & Tinggi & 7,0 \\
\hline & Rendah & 53,0 \\
\hline \multicolumn{3}{|c|}{ Skala 5 Mf (Maculinity-Femininity) } \\
\hline \multirow{2}{*}{ T Score } & Tinggi & 2,0 \\
\hline & Rendah & 47,0 \\
\hline \multicolumn{3}{|c|}{ Skala 6 Pa (Paranoia) } \\
\hline \multirow{2}{*}{ T Score } & Tinggi & 10,0 \\
\hline & Rendah & 40,0 \\
\hline \multicolumn{3}{|c|}{ Skala7 Pt (Psychastenia) } \\
\hline \multirow{2}{*}{ T Score } & Tinggi & 18,0 \\
\hline & Rendah & 41,0 \\
\hline \multicolumn{3}{|c|}{ Skala 8 Sc (Schizophrenia) } \\
\hline \multirow{2}{*}{ T Score } & Tinggi & 12,0 \\
\hline & Rendah & 51,0 \\
\hline \multicolumn{3}{|c|}{ Skala 9 Ma (Hypomania) } \\
\hline \multirow{2}{*}{ T Score } & Tinggi & 2,0 \\
\hline & Rendah & 65,0 \\
\hline \multicolumn{3}{|c|}{ Skala 0 Si (Social Introversion) } \\
\hline \multirow{2}{*}{ T Score } & Tinggi & 28,0 \\
\hline & Rendah & 23,0 \\
\hline
\end{tabular}

Tabel 5 menunjukkan bahwa dari beberapa mahasiswa dengan persentase skala klinis yang tinggi, didapatkan skor 
tinggi pada skala subklinis. Empat skala yang paling menonjol pada skala subklinis berturut-turut ialah: $\mathrm{D}_{1}(88,9 \%), \quad \mathrm{Si}_{1}$ $(82,1 \%), \mathrm{D}_{4}(81,5 \%)$, dan $\mathrm{D}_{5}(63 \%)$.

Tabel 5. Distribusi mahasiswa berdasarkan status mental menurut skala subklinis.

\begin{tabular}{|c|c|c|c|}
\hline $\begin{array}{l}\text { Skala } \\
\text { Klinis } \\
\end{array}$ & $\begin{array}{c}\text { Skala } \\
\text { Subklinis } \\
\end{array}$ & $\mathbf{n}$ & $(\%)$ \\
\hline \multirow{5}{*}{$\begin{array}{c}\mathrm{D} \\
(27 \%)\end{array}$} & $\overline{D_{1}}$ & 24 & 88,9 \\
\hline & $\mathrm{D}_{2}$ & 8 & 29,6 \\
\hline & $\mathrm{D}_{3}$ & 13 & 48,1 \\
\hline & $\mathrm{D}_{4}$ & 22 & 81,5 \\
\hline & $\mathrm{D}_{5}$ & 17 & 63,0 \\
\hline \multirow{5}{*}{$\begin{array}{c}\mathrm{Hy} \\
(10 \%)\end{array}$} & $\mathrm{Hy}_{1}$ & 1 & 10,0 \\
\hline & $\mathrm{Hy}_{2}$ & - & - \\
\hline & $\mathrm{Hy}_{3}$ & 8 & 80,0 \\
\hline & $\mathrm{Hy}_{4}$ & 5 & 50,0 \\
\hline & $\mathrm{Hy}_{5}$ & - & - \\
\hline \multirow{5}{*}{$\begin{array}{c}\mathrm{Pd} \\
(27 \%)\end{array}$} & $\mathrm{Pd}_{1}$ & 4 & 57,1 \\
\hline & $\mathrm{Pd}_{2}$ & 1 & 14,3 \\
\hline & $\mathrm{Pd}_{3}$ & - & - \\
\hline & $\mathrm{Pd}_{4}$ & 3 & 42,9 \\
\hline & $\mathrm{Pd}_{5}$ & 4 & 57,1 \\
\hline \multirow{3}{*}{$\begin{array}{c}\mathrm{Pa} \\
(10 \%)\end{array}$} & $\mathrm{Pa}_{1}$ & 9 & 90,0 \\
\hline & $\mathrm{Pa}_{2}$ & 3 & 30,0 \\
\hline & $\mathrm{Pa}_{3}$ & - & - \\
\hline \multirow{6}{*}{$\begin{array}{c}\mathrm{Sc} \\
(12 \%)\end{array}$} & $\mathrm{Sc}_{1}$ & 7 & 58,3 \\
\hline & $\mathrm{Sc}_{2}$ & 5 & 41,7 \\
\hline & $\mathrm{Sc}_{3}$ & 8 & 66,7 \\
\hline & $\mathrm{Sc}_{4}$ & 11 & 91,7 \\
\hline & $\mathrm{Sc}_{5}$ & 5 & 41,7 \\
\hline & $\mathrm{Sc}_{6}$ & 3 & 25,0 \\
\hline \multirow{4}{*}{$\begin{array}{c}\mathrm{Ma} \\
(2 \%)\end{array}$} & $\mathrm{Ma}_{1}$ & - & - \\
\hline & $\mathrm{Ma}_{2}$ & - & - \\
\hline & $\mathrm{Ma}_{3}$ & - & - \\
\hline & $\mathrm{Ma}_{4}$ & 1 & 50,0 \\
\hline \multirow{3}{*}{$\begin{array}{c}\mathrm{Si} \\
(28 \%)\end{array}$} & $\mathrm{Si}_{1}$ & 23 & 82,1 \\
\hline & $\mathrm{Si}_{2}$ & 12 & 42,9 \\
\hline & $\mathrm{Si}_{3}$ & 12 & 42,9 \\
\hline
\end{tabular}

\section{BAHASAN}

Dalam bahasan ini, peneliti membatasi pada skala klinis dengan hasil yang tinggi. Skala klinis yang paling menonjol dari semua skala yaitu skala klinis Si (social introversion) yang mempunyai persentase tinggi (28\%) dengan interpretasi skor tinggi individu tampak sangat menarik diri, pemalu, introver, dan pesimis. Skala klinis
$\mathrm{D}$ (depression) juga menunjukkan hasil yang tinggi (27\%) dengan interpretasi skor tinggi memperlihatkan perasaan depresi, tidak bahagia, pesimis tentang masa depan, kurang percaya diri, sering merasa bersalah, serta mudah lelah dan pasif. ${ }^{11}$ Hasil penelitian ini lebih rendah dibandingkan hasil penelitian sebelumnya yang dilakukan oleh Singh et al. $^{12}$ yang mendapatkan 34,4\% mahasiswa kedokteran tahun ketiga masa perkuliahan memiliki gejala depresi.

Skala subklinis dapatdi intrepretasikan jika skala klinis menunjukkan hasil yang tinggi. Empat skala subklinis dengan skor tinggi yang paling menonjol ialah: $\mathrm{D}_{1}$ sebanyak 24 orang $(88,9 \%)$ dengan interpretasi skor tinggi menunjukkan perasaan depresi, tidak bahagia, tidak percaya diri, dan rasa bersalah; $\mathrm{Si}_{1}$ sebanyak 23 orang $(82,1 \%)$ dengan interpretasi skor tinggi tampak pemalu dan tidak nyaman dalam situasi sosial; $\mathrm{D}_{4}$ sebanyak 22 orang $(81,5 \%)$ dengan interpretasi skor tinggi menunjukkan individu mengalami gangguan konsentrasi, memori, dan kebijakan; dan $\mathrm{D}_{5}$ sebanyak 17 orang dengan interpretasi skor tinggi individu merasa hidup tak ada artinya. $^{11}$

\section{SIMPULAN}

Dari hasil penelitian dapat disimpulkan bahwa berdasarkan skala klinis dan sub-klinis MMPI-2 adaptasi Indonesia, pada mahasiswa semester 5 Fakultas Kedokteran Universitas Sam Ratulangi Manado TA 2012/2013 skala yang tinggi dan skala yang menonjol ialah depression dan social introversion.

\section{UCAPAN TERIMA KASIH}

Ucapan terima kasih ditujukan kepada semua pihak yang secara langsung maupun tidak langsung telah menumbuhkan ide dan gagasan pada penulis.

\section{DAFTAR PUSTAKA}

1. Sunaryo. Psikologi untuk Keperawatan. Jakarta: EGC, 2002; p.1. 
2. Santrock JW. Adolescence: Perkembangan Remaja. Jakarta: Erlangga, 2003; p.25-6.

3. Gunawati R, Hartati S, Listiara A. Hubungan antara efektivitas komunikasi mahasiswa-dosen pembimbing utama skripsi dengan stres dalam menyusun skripsi pada mahasiswa Program Studi Psikologi Fakultas Kedokteran Universitas Diponegoro. Jurnal Psikologi Universitas Diponegoro. 2006;3(2):93-115.

4. Kaplan HI, Sadock BJ, Grebb JA. Sinopsis Psikiatri: Ilmu Pengetahuan Perilaku Psikiatri Klinis Jilid I. Jakarta: Binarupa Aksara; 2010.

5. Hidayat DR. Permasalahan mahasiswa. Jakarta: Universitas Negeri Jakarta; c2011[cited 2012 Oct 21]. Available from: http://www.kopertis3.or.id/ $\mathrm{html} / \mathrm{wp}$-content/uploads/2011/04/per masalahan-mahasiswa-2.pdf.

6. Liza RG. Gangguan Mental Emosional pada Ibu Pasien Skizofrenia yang Berobat ke Poliklinik Psikiatri BLUD RSJ Provinsi Sumatera Utara [Tesis]. Medan; Universitas Sumatera Utara; 2012.

7. Lestari DR. Penggunaan Electronic Patient Record pada Pelayanan Keperawatan
Jiwa [refarat]. Jakarta: Universitas Indonesia; 2011. Available from: http://www.fik.ui.ac.id/pkko/files/UTS_ SIM.Dhian\%20Ririn\%20Lestari.S2Jiw a.ok.pdf

8. Illiades C. College Illness aren't Always Physical.c2011 [updated 2011 Apr 27; cited 2012 Oct 21]. Available from: http://www.everydayhealth.com/college -health-pictures/ college-illnesses-arentalways-physical.aspx.

9. Eisenberg D, Golberstein E, Hunt J. Mental Health and Academic Success in College. B.E. Journal of Economic Analysis \& Policy. 2009;9(1):1-40.

10. Butcher JN. MMPI-2 (Minnesota Multiphasic Personality Inventory-2). c1989 [updated 2009; cited 2012 Oct 30]. Available from: www.pearson assessments.com/mmpi2.aspx

11. Kasan H. Buku Panduan Workshop MMPI-2 (Advanced) Professional Training Center "WNL". Jakarta. 2008.

12. Singh A, Lal A, Sheckhar. Prevalence of depression among medical students of a private Medical College in India. Online Journal of Health and Allied Sciences. 2010;9(4):8. 